\title{
Web phenomenon applied as ICT platform in support of business model innovation
}

\author{
C.J.H. Steenkamp \\ steenkampcjh@tut.ac.za
}

S.E. Arnoldi-van der Walt

arnoldivanderwaltse@tut.ac.za

Department of Public Relations and Business Communication

Tshwane University of Technology

Pretoria

\section{Contents}

1. Introduction

2. Traditional business model

3. World-Wide Web (Web) phenomenon's contribution as business communication medium and information and communication (ICT) platform in the process of business model innovation

4. Business Model Innovation (BMI) concept

5. Conclusion

6. References

\section{Introduction}

Toffler described the characteristics of the 21st century society with the words 'rapid change, the accelerated pace of life, temporariness, instability, variation' and 'novelty' as far back as in 1971, in his book Future Shock. He foresaw a total new society, activated and controlled by technology. Some of his predictions have already come true - the rapid change in individual needs, the accelerated pace of change, the consequential demise of bureaucracy in organizations and the 'near-instantaneous communication across the globe' (Matthee 1998; Toffler 1971), as provided by the Internet.

The impact of the transition from the industrial society to the new information society has been compared to the impact of the industrial revolution, during which society changed from a decentralized feudal society into a society with a centralized industrial economy. Other than was the case with the industrial revolution, the information revolution is taking place at a rate never before witnessed in history (Hjorth 1997). The development of the Internet was a major step forward in the information revolution, and it would soon be changing the manner in which companies conducted their business. It emerged from ideas about nonlinear information organization, associative linking and existing information systems (information technology) and followed the traditional path of development from the basic invention phase to a period of refinement and, finally, to a period of innovation, affording people a motive and means for adopting the technology. The Internet's development can be traced as far back as 1969, although the enormous potential to manage information through this new technology was only realised in 1993, when its powerful information communication capabilities in the form of the 'new medium', the World-Wide Web, were discovered internationally (An overview ... 2000; Internet began ...1999; RUN when you hear this ..., n.d. Boraski 2001a). 


\section{Traditional business model}

The traditional organizational business model [developed more than a century ago in Britain as 'the method of doing business by which a company can sustain itself - that is to generate revenue' (Rappa, 2001)]' was driven by pre-specific plans and goals, aimed to ensure optimisation based primarily on building consensus, convergence and compliance' (Malhotra 2000b).

In this traditional model ['tightly bound command-and-control hierarchy with headquarters staff calling the shots from the top' (Viscio and Pasternack 1996)], organizational information and control systems, performance and behaviour were modelled on the same paradigm, to enable convergence by ensuring adherence to the organizational tried-and-true model, the company way, rules of thumb, procedures, processes and archived best practices to ensure profits and sustainability. As described by Malhotra in his article, A Framework for Business Model Innovation, this routinization of organizational goals for realizing increased efficiencies is suitable for that era, which is marked by a relatively stable and predictable business environment (Malhotra 2000b). 'The pace of change was relatively predictable with some level of certainty', while the components to sustain success ('information, control and performance systems; the procedure manuals, rules of thumbs and best practices in the minds of managers and workers who have comfort in following "tried and tested" business practices') is safely and comfortably embedded in the company's recipe for success (Malhotra 2000a).

In the traditional economy, business dictated to customers and customers had to buy what organizations had to offer them to suit their needs. Customers' needs were artificially created and manipulated; therefore, the service and products rendered to them could be planned in advance. It is clear that the old world of business, with its predefined recipes for success and pre-determined strategies and business conduct, was focused on its inner self and its products. Business existed in a comfort zone and organizations were able to programme and archive their business procedures and know-how in databases and human minds for any significant duration of time as 'programmed logic' (Malhotra 2000a).

\subsection{How did business communication reflect this reality?}

Communication has always been the vehicle used by individuals and groups (organizations), whereby the parties involved could benefit from each other through cooperation and interaction (Knowledge Management 2001). Human interaction, according to Giddens (Mathhee 1998:206), involves the communication of meaning. To be a participant in the interaction process, the individual draws (through communication processes) from mutual stocks of information and knowledge imbedded in organizational structures to give sense to his or her actions and the objects he or she produces.

\subsection{Changes brought about by technology}

Information and communication technology has brought about specific irreversible changes to the traditional business model; originated by the dynamic and informative opportunities it has presented to both customers and businesses, causing business to accelerate at a pace that most corporations cannot keep up with nor adjust to. Bill Gates summarizes it as a shift from that of mechanization and industrialization towards a truly global economy based on information flow.

It has caused 21st century leading-edge corporations to give up the command-and-control leadership style, break down hierarchies, move over departmental boundaries, embrace teamwork, encourage flexibility and establish a value chain within the organization (Ashkenas et al. 1996). Technology has empowered customers and markets to dictate, and forced business to comply with their individual and undefined needs. It has caused the business model to become flatter, larger and more scattered and the focus of business to change from product and production to the customer and his or her undefined needs, preferences and abilities - creating a new world of business and the new business model. Successful customer relation management (CRM) organizations are those that make the transition from a product focus to a customer focus, tailoring products to meet the needs of individual customers. 


\subsection{New customer faces the new employee}

The pace of change in this new world of business is hitting a new level - managers and workers now have to facilitate learning and unlearning, 'thinking-out-of-the-box' and 'deliver-on-the-fly'. Malhotra (1999) indicates that employees and business processes have become the core competencies of the new 21st century business model. Employees are expected to respond and adapt to the specific and undefined needs and requests of each customer and to deliver a product or service on demand. As the frontline service providers, they are strategically co-responsible for the successes of the organization. To achieve those successes, employees rely on their organizations to supply them with correct information so that they can give fresh interpretations of and responses to the available information, based on context and content in relation to the new requests (and information) they receive from their organizations' 'new customers' in their business interactions with them (Malhotra 1999; Malhotra 2000c).

\subsection{Information technology (IT) to the rescue}

To support their employees, organizations had to create information and communication systems that could rapidly adapt their 'programmed logic' and allow a multi-direction, inter-organizational flow of information and interaction between employees and between employees and customers to take place (Malhotra 2000c). The earlier involvement of information technology (IT) in supporting organizations in their transition to the new business model was its development of information processing systems to enhance the business processes of organizations (Malhotra 2000b). This was followed by ITs development of smarter systems by which IT managers archived knowledge in organizational databases management information systems (MIS) with the aim of spreading human intelligence throughout the organization in their efforts to re-engineer and optimize the organizations' business processes for the new business environment - better known as the era of business process reengineering (BPR) (Malhotra 2001a).

In the new business model, these IT systems with their unidirectional information flow and top-down structures could not make provision for the diverse interpretations of archived and new information needed to produce a large repertoire of responses to meet the wide variety of demands and continuous changing needs and requests of these 'new customers' (Malhotra 2000c). Their great diversity in architecture and lack of communication abilities caused these information systems to fail in facilitating the direct, immediate and continuous interaction between customer-and-supplier and supplier-andsupplier that was necessary to enable the supplier to customize the product to the customer's needs (Strategic Dynamic, n.d. Dynamic Internet 2000).

\subsection{Appearance and realization of the Web as business communication medium or, in IT terminology, as an information and communication technology platform}

In 1993, enormous potential was unleashed by the official operational entrance of the Web into the world of communications and business, not only to manage information worldwide, but also for dynamic support to and changes in business processes in the business world. Major changes occurred in companies and in the manner in which people communicated.

The Web's first involvement in the new business environment was not so successful. With the appearance of the Web in the new business world, many organizations were overwhelmed by its globalization, virtualization and immediacy characteristics. These features of the Web soon added 'magical powers' to the already optimistic image it had in the new business world. Many organizations, blinded by this magical image, applied the Web to optimize and streamline their traditional business processes - that is, to boost their sales. Unfortunately, the new business economy and the new business model required human involvement and a customer-focused approach, and the Web involvement consequently led to the dot-com crash. It is evident from studies done on crashed dot-com enterprizes that these unsuccessful enterprizes were part of 'an era of unbridled optimism and outright greed'. They set out to build business empires where sales came first, using the Web statically to achieve this goal, 'while there was little regard as to whether their products were [even] suited for sale via the Web' (The Fall of a Dot-Com 2000).

Research into the dynamic and interactive communication capabilities and nature of the Web indicated that the Web with its open, collaborative and non-hierarchical architecture, made possible a total networked paradigm, which could provide an organization with exciting opportunities to create direct and interactive access for employees and customers alike (Dynamic Internet 2000; Lindren 2000; Malhotra 1999; Malhotra 2000c; Morris and Ogan 1996, Pant and Hsu 1996; Why should our company 
As a result of the appearance of new, dynamic Web technology and pressure from the new business model, the focus of the Web in organizations shifted in the past few years from a marketing tool to an enterprise-strategy business communication medium and information and communication platform.

\section{Business model innovation (BMI) concept}

According to a theory held by Malhotra (2000c), as discussed in a series of articles on his host Web site, http://@brint.com, the new e-world of business has evolved over the last two to three years. This theory comprises the business model innovation concept, which entails the continuous reassessment of the organization's knowledge management strategy to empower its employees to keep pace with the dynamics of the new business environment in order to meet the undefined needs of its customers (Malhotra 2000b). According to Malhotra, all 'programmed logic' and organizational routines of an organization require continuous reassessment to ensure that employees receive the correct information to produce a certain action . This reassessment includes the fresh interpretation and regeneration of information (knowledge) by employees, based on the information they receive from each customer's request and on information they retrieve from the 'programmed logic' (Malhotra 2000c).

\subsection{Web phenomenon's role and position as business communication medium and social construction within the concept of BMI}

The unique communication and virtualization capabilities of the Web, supported by dynamic Web technology, deliver a phenomenon to the e-world of business, a virtual reality with a well-known (common) area, a subjective context and living space for human interaction and the retrieval and delivery of information and knowledge. It separates itself from the technology by which it is generated and becomes a social construction; the technology becomes merely a tool ; a strategic 'business communication instrument'; a dynamic application and a medium that accommodates the multidirectional flow of information (Malhotra 2000b).

The dynamic Web phenomenon is more than IT; it is a new way of human interaction, a new culture of doing and existing. Malhotra's theory (2000b) clearly identifies the interdependence and role of the human factor and the Web as the business communication medium of choice for the new e-world of business.

\section{Conclusion}

\subsection{Traditional business model}

- The business processes of the traditional business model were driven by pre-specific plans and goals aimed at ensuring optimization of its products, based primarily on building consensus, convergence and compliance.

- Its information and control systems and the performance and behaviour of employees were controlled from the top by management to ensure adherence to the organizational tried-and-true model, the company's way of doing, rules of thumb, procedures, processes and best practices, in order to ensure results and success.

- The rate of change was relatively predictable, with some level of certainty, and every process was safely and comfortably embedded in the company's recipe for success (programmed logic), that is, human minds and company databases. As long as information technology services could provide this service, they were sufficient.

- The business focus was product-orientated. The main aim of the organization was to sell its products and to make money. Customers had to buy what organizations had to offer.

\subsection{New business model}

- Technology caused the traditional business model to become flatter and its area of delivery 
became larger and more scattered.

- The enhanced information base delivered by the Web empowered customers to dictate the service they needed. This changed the business focus from being product-orientated to being customer-orientated.

- Employees became the frontline service providers and management had to break down its command-and-control management methodology and remove boundaries to enable a flow of information within the organization to take place so that employees could serve the customers' undefined needs.

- Organizations were also responsible for providing employees with a tool to retrieve information to serve their customers' individual needs and store newly created knowledge and solutions.

- Existing information technology systems were unidirectional information delivery mechanisms and were unable to support the human interaction and communication that were required for the new business interaction processes of the new business model. A more appropriate business communication medium was needed.

\subsection{Business model innovation}

Business model innovation (BMI) stands in strong contrast to business process re-engineering (BPR). BPR promotes the re-engineering and optimization of business processes to maximize production. BMI promotes the innovation of the total business model of an organization in order to become customerfocused. It identifies human involvement in, and interaction with, customized products according to customers' specific needs as the core activity of the new business model. According to Malhotra (2000b), the adoption of BMI implies the following:

- It requires the continuous reassessment of the 'programmed logic' and organizational routines of an organization to ensure that management and employees keep pace with the dynamics of the new business environment.

- It also requires that the employee, as frontline service provider, be enabled to retrieve information, create new knowledge and produce a wide variety of responses (certain actions, based on the information he or she receives). It also requires that the employee be provided with information flow and the Web as information and communication medium through which he or she can interact with the information and his client.

- Malhotra (2000b) identifies the unique interactive communication characteristics of the Web and states that the Web should be more medium and less technology. The IT infrastructure is recognized as technology and the Web is seen as information and communication platform, a virtual space for human interaction and relationship building in the new business environment.

- It is evident that organizations will not be successful if they adopt the Web to optimize their business model without applying the business model innovation concept. Business model innovation is a component of the Web phenomenon and should form part of its adoption and deployment.

\subsection{Application of the Web}

- Various researchers agree that the Web, with its immediacy and direct interactive and total networked capabilities, is the ideal information communication technology to serve the new business model as business communication medium.

- The social structures provided by the Web phenomenon not only support the total spectrum of human interaction in the business environment, from global mass communication to interpersonal interaction inspired by survival, but they also create a psychological comfort zone for the employee and customer through the known and personalized virtual space created by the concept of cyberspace. The Web phenomenon 'acts as a resource, embodying means and materials of human labour', allowing human interaction and cooperative work (Matthee 1998:220).

- Within this context of being a social construction and business communication's medium, the Web phenomenon's dynamic characteristics demonstrate its capacity to sustain social interaction, mediate collaboration and deliver a business information and communication service to the new business environment. It enables the organization to:

$\circ$ accommodate every individual customer by tailoring the product and information according to each customer's preferences, abilities and needs;

○ satisfy the customer's undefined needs by means of the most current information; and

- bring information as close as possible to the employee, who, as the frontline service 
provider of the organization, has to be able to modify and adapt information rapidly in line with customers' individual needs, to create new responses on the information he or she receives and to deliver a product on demand.

\section{References}

Boraski, C. 2001a. The WWW: evolution of a new communication medium. [Online]. Available WWW: http://www.boraski.com/www/intro.html (Accessed 10 August 2001).

Dynamic Internet. 2000. [Online]. Available WWW: http://usweb.se-com.com.

(Accessed 17 November 2000).

The Fall of a dot-com. 2000. [Online]. Available WWW:

http://www.businessweek.com:/2000/00_18/ b3679001.htm?scriptFramed.

(Accessed 10 December 2001).

Finkelstein, C. 1999. Business re-engineering and the Internet: transforming business for a connected world. [Online]. Available WWW: http://www.ies.aust.com/ ieinfo/. (Accessed15 October 2000).

Hjorth A, 1997. Why an intranet presence? [Online]. Available WWW:

http://www.innovell.com/infr/strategy2.htm. (Accessed: 25 April 2000).

Internet began 30 years ago at UCLA. 1999. [Online].

Available WWW: http://www.engineer.ucla.edu/netis30.htm. (Accessed 21 December 2000).

Knowledge management - the evolution of man and machine. 2001. [Online].

Available WWW: http://www.microsoft.com/europe/business/Corp_portals/288.htm.

(Accessed 20 August. 2001).

Lindren, L.M. 2000. Application servers: the next wave in corporate intranets and Internet access. 2000. [Online]. Available WWW: http://www.brint.com/members/online/ 200402/apps/apps.html. (Accessed 11 November 2000).

Malhotra, Y. 1999. Intellectual capitalism: Does KM = IT. [Online]. Available WWW:

http://www.brint.com/advisor/a091599.htm. (Accessed 25 June 2001).

Malhotra, Y. 2000a. Knowledge management and e-business in the new millennium. [Online].

Available WWW: http://www.brint.com/advisor/a011700.htm. (Accessed 3 July 2001).

Malhotra, Y. 2000b. Knowledge management and new organization forms: A framework for business model innovation. [Online]. Available WWW:

http://www.brint.com/members/01030526/businessmodelinnovation/businessmodelinnovation_1.html.

(Accessed 25 June 2001).

Malhotra, Y. 2000c. Knowledge management for e-business performance: advancing information strategy to 'Internet time'. [Online].

Available WWW: http://www.brint.com/papers/kmebiz/kmebiz.html. (Accessed 8 November 2000).

Malhotra Y, 2001. What is really knowledge management? Crossing the chasm of hype. [Online]. Available WWW: http://www.brint.com/advisor/a092099.htm. (Accessed 25 June 2001).

Matthee, C.M. 1998. Supporting the teaching of mathematics by information technology in a cooperative learning environment. Doctoral dissertation. University of Pretoria.

Morris, M. and Ogan, C. 1996. The Internet as mass medium. [Online].

Available WWW: http://jcmc.huji.ac.il/vol1/issue4/morris.html. (Accessed 10 August. 2001). 
An overview of the World Wide Web. 2000. [Online].

Available WWW: http://docs.rinet.ru/cgi3.2/ch1.htm. (Accessed 12 October 2000).

Pant, S. and Hsu, C. 1996. Business on the Web: strategies and economics. [Online]. Available WWW: http://www5conf.inria.fr/fich_html/papers/P51/Overview.html. (Accessed 16 November 2000).

Rappa, M. 2001. Managing the digital enterprise, business models on the Web. [Online]. Available WWW: http://www.strategy business.com/research/96201/page1.html. (Accessed 16 November 2000).

RUN when you hear this question: why should I get on the Internet? n.d. [Online]. Available WWW: http://www.businessla.com/business/13.htm. (Accessed 20 July 2000).

Strategic Dynamic. n.d. [Online]. Available WWW: http://usweb.se-com.com/ (Accessed 17 November 2000).

Toffler, A. 1971. Future shock. London and Sydney: Pan Books.

Viscio, A.J. and Pasternack, A. 1996. Toward a new business model. [Online].

Available WWW: http://ecommerce.ncsu.edu/business_models.html. (Accessed 23 February 2001).

Why should our company be on the Internet? [Online]. 1999.

Available WWW: http://www.creativedata.net/background.asp. (Accessed 11 September 2000).

\section{Disclaimer}

Articles published in SAJIM are the opinions of the authors and do not necessarily reflect the opinion of the Editor, Board, Publisher, Webmaster or the Rand Afrikaans University. The user hereby waives any claim he/she/they may have or acquire against the publisher, its suppliers, licensees and sub licensees and indemnifies all said persons from any claims, lawsuits, proceedings, costs, special, incidental, consequential or indirect damages, including damages for loss of profits, loss of business or downtime arising out of or relating to the user's use of the Website. 
ISSN 1560-683X

Published by InterWord Communications for the Centre for Research in Web-based Applications, Rand Afrikaans University 